NOTICE: this is the author's version of a work that was accepted for publication by the American Society of Civil Engineers. The published version is available at http://cedb.asce.org/cgi/WWWdisplay.cgi?261195 


\title{
Utilization of Shredded Rubber Tires for Cement-Stabilized Soft Clays
}

\author{
Mohamed A. Shahin ${ }^{1}$ and Liao S. Hong ${ }^{2}$ \\ ${ }^{1}$ Senior Lecturer, Department of Civil Engineering, Curtin University of Technology, GPO Box U1987, \\ Perth Western Australia 6845, Australia; m.shahin@curtin.edu.au \\ ${ }^{2}$ Graduate Student, Department of Civil Engineering, Curtin University of Technology, GPO Box \\ U1987, Perth Western Australia 6845, Australia
}

\begin{abstract}
Tire-soil mixtures can be used as good construction materials in many geotechnical engineering applications such as pavement foundations, lightweight fill in road embankments and lightweight backfill behind retaining walls. This paper describes research undertaken to investigate experimentally the impact of shredded rubber tires as reinforcing material on the mechanical properties of cement-stabilized soft clay, in terms of strength and stiffness. A series of laboratory experiments are carried out on cement-stabilized clay mixed with several portions of shredded rubber tires of sizes $440 \mu \mathrm{m}$ and $4 \mathrm{~mm}$. The tests conducted include compaction, unconfined compression strength and indirect tensile strength. The results demonstrate that the use of shredded rubber tires has a potential in enhancing the ductility of cementstabilized soft clay but decreases stiffness and ultimate resistance.
\end{abstract}

\section{INTRODUCTION}

The re-use of waste materials is a primitive step in creating a sustainable future, and due to increasing waste disposal cost, the re-use of waste and recycled materials is increasing worldwide and becoming more popular in civil engineering (Edincliler et al. 2004). The literature indicates that the addition of recycled car tires in the form of tire shreds or chips to soil enhances the engineering properties of the mixture. Research into soil-tire mixtures (e.g. Hataf and Rahimi 2006; Madesic et al. 2009; Zornberg et al. 2004) indicates that adding an adequate amount of tire chips/shreds to sand can generally improve the shear strength characteristics of the mixture, even though compressibility increases. However, full understanding of the engineering behavior of these materials is essential so that they can be used safely in civil engineering applications. In Australia, 20 million used car tires are disposed annually, causing fire and environmental health hazard problems. This urges the need for an alternative, environmentally friendly way of tire disposal. The study presented in this paper is part of an ongoing research to provide good means of consuming the millions of scrap tires that are generated annually in Australia so as to save the available land 
that would otherwise be taken for stockpiling of used tires. The study also aims to allow construction over poor quality soils (such as soft clay) by solving the technical problems associated with the instability of constructing over such unstable soils and thus reducing quarrying of the natural resources.

Soft clay is a problematic soil that exhibits low bearing capacity and high compressibility under loading and thus, chemical stabilization by the addition of lime or cement is commonly used to improve the geotechnical properties of soft clay. However, while lime-cement treatment enhances the compressibility and shear strength of soft clay, it decreases the ductility of treated soil, leading to brittle material behavior. In order to improve the ductility of chemically stabilized soils, conventional geosynthetics (e.g. strips, geotextile, geogrid, etc.) are usually used as soil reinforcement. More recently, randomly distributed fibers are also used (e.g. Shahin and Harris 2010), which have found to provide more advantages over conventional geosynthetics in terms of workability and simplicity of adding and mixing the fibers with soil. The aim of the current work is to investigate the effects of shredded rubber tires in enhancing the engineering characteristics of cement-stabilized soft clay, especially ductility.

\section{MATERIAL TESTED}

The clay used in this study has a specific gravity of 2.6, liquid limit of $51 \%$ and plastic limit of $28 \%$. It is classified as $\mathrm{CH}$ by the Unified Soil Classification System (USCS). The clay was stabilized with $15 \%$ (by weight of dry soil) of general purpose ordinary Portland cement. Two different sizes of shredded rubber tires, i.e. tire powder of $440 \mu \mathrm{m}$ and tire grains of $4 \mathrm{~mm}$, are added to cement-stabilized clay at $1 \%$, $4 \%$ and $7 \%$ (by weight of dry soil). The shredded tires are by-products of used vehicle tires that are manufactured by a local company where a series of tire shredders and magnets are used to produce a clean and consistent grade of rubber crumb. The shredded tires have a specific gravity of 1.1, which is lower than the typical values of 2-3 for most materials. Figure 1 shows photographs of the tire grains and powder used.
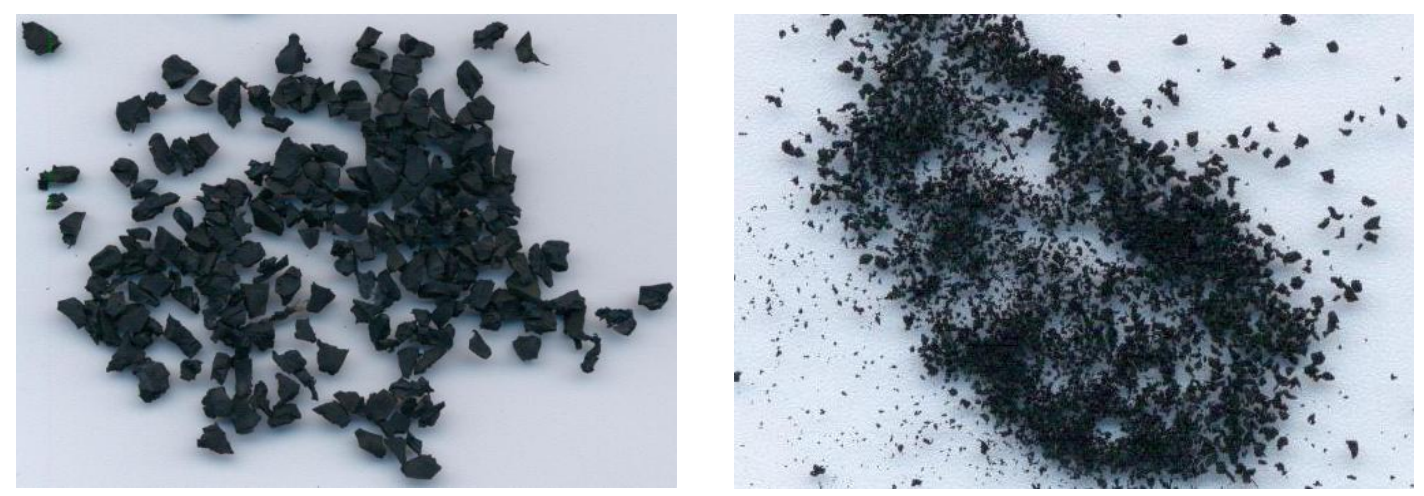

FIG. 1. Photographs showing the grain (left) and tire powder (right) used. 


\section{TESTING PROGRAM AND RESULTS}

\section{Sample preparation}

As mentioned previously, the clay soil specimens used in this study were stabilized with $15 \%$ (by weight of dry soil) of cement and three different amounts by weight of dry soil (i.e. 1\%, 4\% and 7\%) of tire grains and powder. A series of compaction Proctor tests were carried out on all test specimens in accordance with the Australian Standards AS 1289 (2007), and the respective maximum dry densities and optimum moisture contents were obtained. In preparation of all specimens for compressive and tensile strength tests, the sample components were mixed using Hobart mixer with the dough mixing attachment. Specimens were mixed for approximately five minutes or until the water was evenly mixed throughout, and the specimens were cured in a curing room for 7 days at a constant temperature of $35^{\circ} \mathrm{C}$.

\section{Unconfined compression tests}

The compressive strength characteristics of the specimens used were obtained through a series of unconfined compression strength (UCS) tests that were conducted on samples of $38 \mathrm{~mm}$ in diameter and $76 \mathrm{~mm}$ high. All specimens were prepared at a constant level of compaction of at least $95 \%$ of that achieved by the standard compaction Proctor tests. The UCS tests were strain controlled with axial loads applied at a rate of $0.6 \mathrm{~mm} / \mathrm{min}$, and the stress-strain curves obtained are shown in Figures 2 and 3 for clay stabilized with $15 \%$ cement and $440 \mu \mathrm{m}$ tire powder or $4 \mathrm{~mm}$ tire grains.

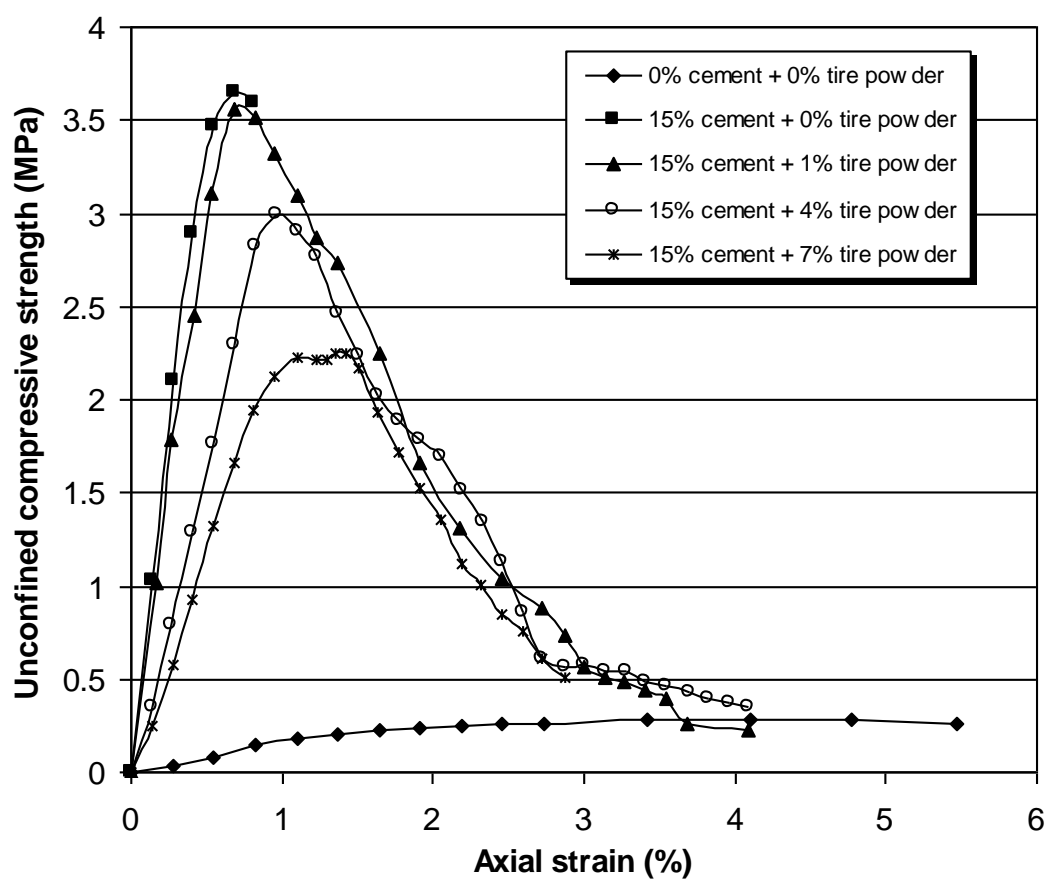

FIG. 2. Results of unconfined compression tests of cement-stabilized soft clay with $440 \mu \mathrm{m}$ tire powder. 


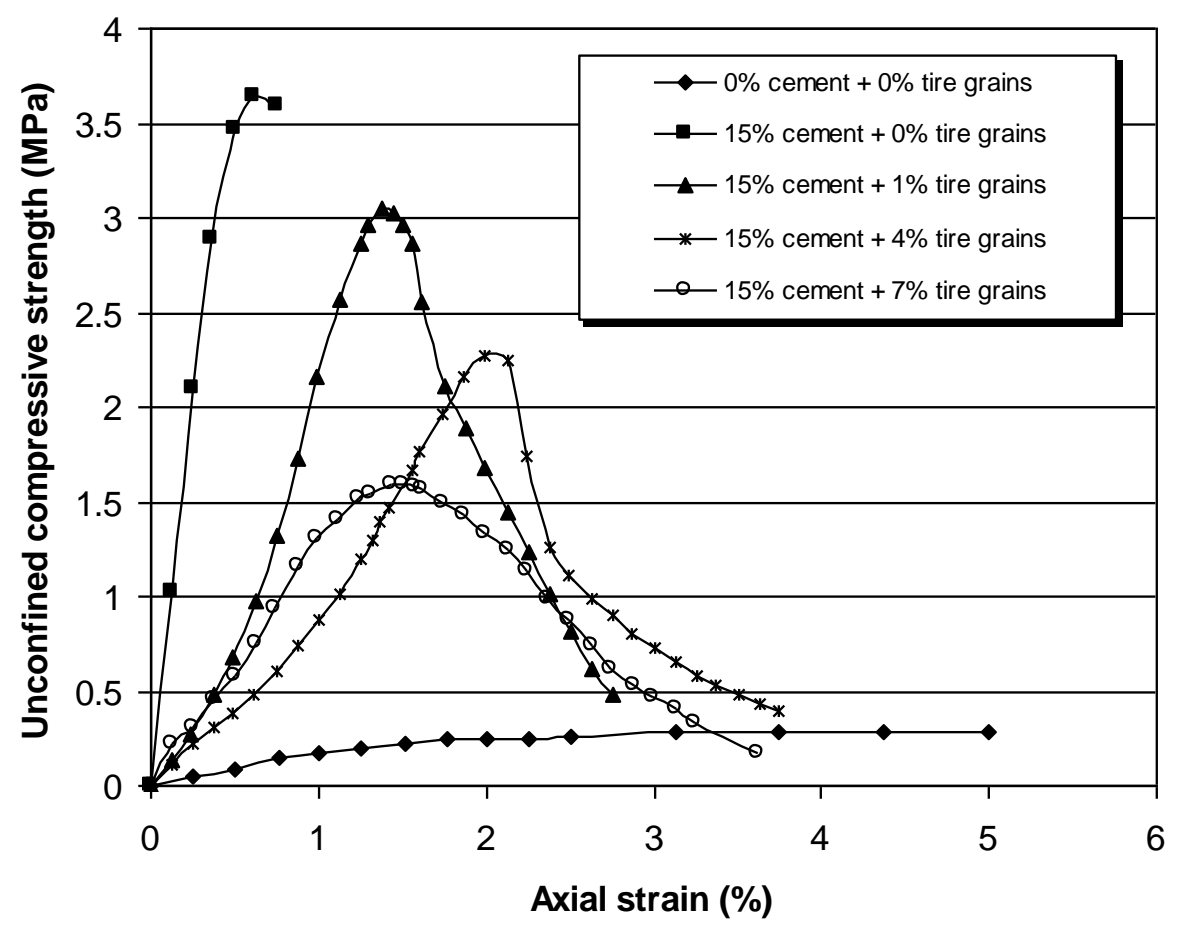

\section{FIG. 3. Results of unconfined compression tests of cement-stabilized soft clay with $4 \mathrm{~mm}$ tire grains.}

It can be seen from Figures 2 and 3 that the addition of cement alone significantly increases the ultimate strength and stiffness (modulus of elasticity) of clay soil, and decreases the deformation at failure. However, it can also be seen that the addition of cement alone exhibits brittle failure with significant loss of post-peak shear strength. On the other hand, it is shown that the addition of shredded rubber tires to cementstabilized clay increases soil ductility regardless of the amount of shredded tires added. This is attributed to the reinforcement impact of shredded tires, which enhance soil ability to restrain cracking.

Figures 2 and 3 also show that stiffness and ultimate compressive strength of cement-stabilized clay seems to decrease by the addition of shredded tires. This is because shredded rubber tires carry small amount of load due to their low elastic modulus relative to the surrounding stabilized soil, leading to reduction in the compressive strength and stiffness of the soil matrix. By comparing the results of Figures 2 and 3, it can also be seen that cement-stabilized clay with tire grains seems to be more prone to the reduction in compressive strength than that of cementstabilized clay with tire powder. For example, the ultimate compressive strength of cement-stabilized clay is decreased by $3 \%$ when $1 \%$ tire powder was used, whereas the compressive strength of cement-stabilized clay is decreased by $20 \%$ when $1 \%$ tire grains were added. This may be attributed to the fact that larger tire sizes create larger weak planes in certain areas in soil matrix due to the loss of bonding between tire grains and surrounding stabilized soil, leading to the development of failure paths when load is applied. This phenomenon was also recognized by Turatsinze et al. (2005) who studied the micrograph of bonding between cement paste and rubber 
shreds. Based on the above results, it is recommended that $1 \%$ tire powder is added to cement-stabilized clay so that the detrimental impact of shredded tire in terms of compressive strength and stiffness is reduced to minimal while keeping better ductility.

\section{Tensile strength tests}

Based on the results obtained earlier from the compressive strength tests, it was decided to conduct the indirect tensile strength test only at $1 \%$ tire powder. The results of the test are shown in Figure 4, which clearly indicate that the tensile strength of soft clay is significantly increased by the addition of cement. However, it is also obviously shown that the tensile behavior of cement-stabilized clay exhibits brittle failure. As shown in Figure 4, the addition of $1 \%$ tire powder significantly enhances the ductility of cement-stabilized clay, even though ultimate tensile strength decreases. Again, this is attributed to the reinforcement impact of rubber tires in increasing the ability of cement-stabilized clay to restrain cracking. It can also be seen from Figure 4 that, on the contrary to the compressive strength tests, the addition of rubber tire to cement-stabilized clay does not reduce the tensile strength modulus of elasticity.

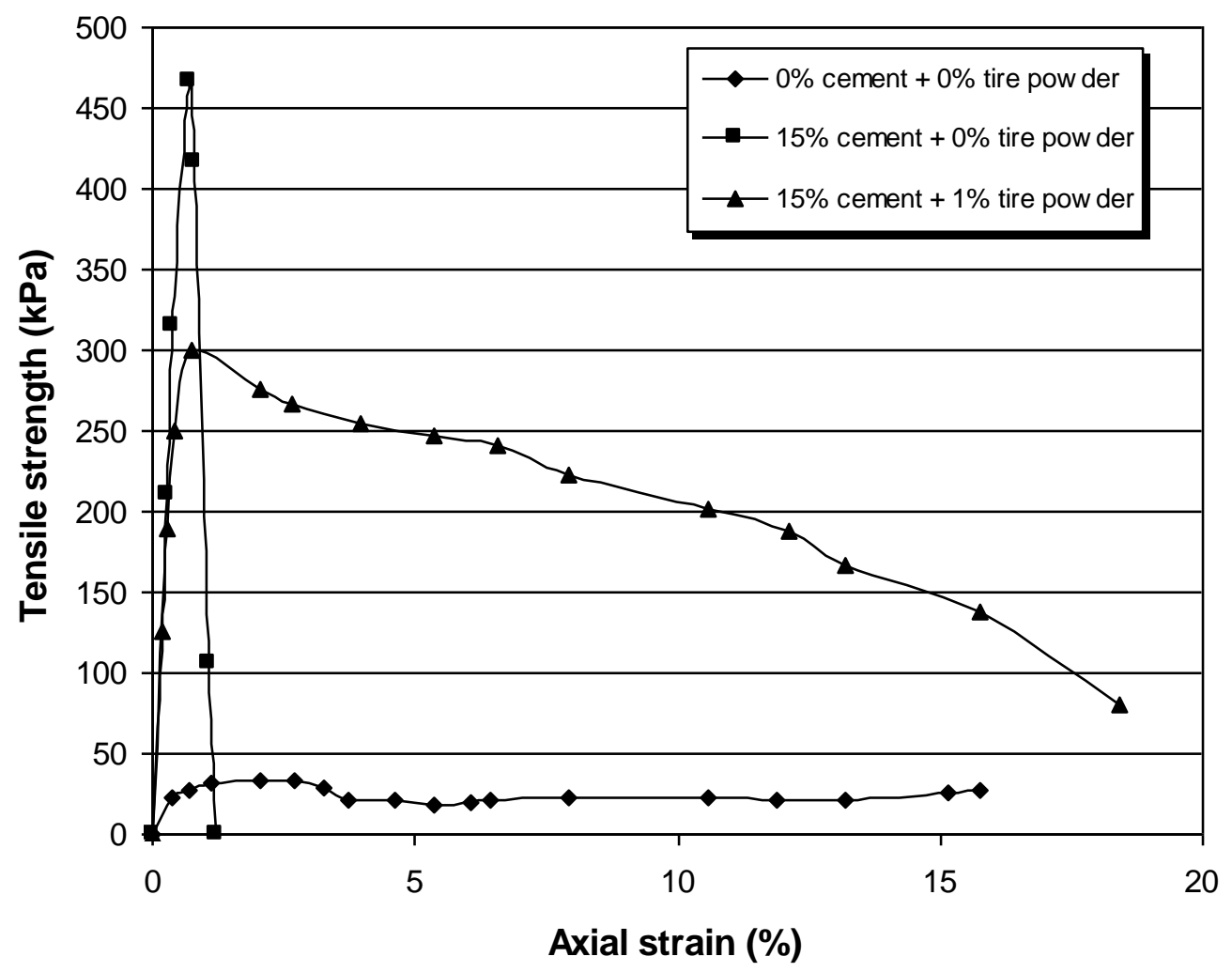

FIG. 4. Results of indirect tensile strength test of cement-stabilized soft clay with $440 \mu \mathrm{m}$ tire powder. 


\section{SUMMARY AND CONCLUSIONS}

A series of laboratory tests were conducted to investigate the effects of shredded rubber tires on the strength and stiffness of cement-stabilized soft clay. The tests conducted include the unconfined compression strength and indirect tensile strength. Cement was added by an amount of $15 \%$ (by weight of dry soil) and two different sizes of shredded tires, i.e. $440 \mu \mathrm{m}$ tire powder and $4 \mathrm{~mm}$ tire grains, were added in order of $1 \%, 4 \%$ and $7 \%$ by weight of dry soil. All experiments were carried out after curing time of 7 days. The study has yielded the following conclusions:

1. The addition of shredded tires increases the compressive strength ductility of cement-stabilized clay regardless of the amount of tire added, but seems to decrease the ultimate compressive strength and compressive modulus of elasticity.

2. The addition of $1 \%$ tire powder (by weight of dry soil) seems to reduce the detrimental impact of shredded tires in decreasing the compressive strength and stiffness of cement-stabilized clay, while keeping better ductility.

3. The addition of $1 \%$ tire powder increases the tensile strength ductility of cementstabilized clay and seems not to decrease the tensile strength modulus of elasticity, even though it decreases the ultimate tensile strength.

\section{ACKNOWLEDGEMENT}

The authors would like to thank Sim Tire Cycle Pty Ltd. (Melbourne, Australia) for providing the tire grains and powder used in this work.

\section{REFERENCES}

Australian Standards AS 1289 (2007). Method of testing soils for engineering purposes.

Edincliler, A., Baykal, G., and Dengili, K. (2004). "Determination of static and dynamic behavior of recycled materials for highways." Resources Conservation and Recycling, 42, 223-237.

Hataf, N., and Rahimi, N. (2006). "Experimental investigation of bearing capacity of sand reinforced with randomly distributed tire shreds." Construction and Building Materials, 20(10), 910-916.

Madesic, T., Shahin, M. A., and Nikraz, H. R. (2009). "Geotechnical properties of red sand mixed with tire grains and powder." 17th International Conference on Soil Mechanics and Geotechnical Engineering, Alexandria, Egypt, 348-351.

Shahin, M. A., and Harris, L. (2010). "Use of fiber for improving engineering characteristics of cement-stabilized soft clays." 9th International Conference on Geosynthetics, Brazil, in press.

Turatsinze, A., Bonnet, S., and Granju, J. L. (2005). "Mechanical characterization of cement-based mortar incorporating rubber aggregates from recycled worn tyres." Building and Environment, 40, 221-226.

Zornberg, J. G., Cabral, A. R., and Viratjandr, C. (2004). "Behavior of tire shred-sand mixtures." Canadian Geotechnical Journal, 41(2), 227-241. 